\title{
Bioremediation of Crude and Refined Oil-Polluted Fresh Water Using Chlorella vulgaris Isolated from a Pond
}

\author{
Onuorah Samuel ${ }^{1, *}$, Okafor Gerald ${ }^{2}$, Nwankwo Joseph ${ }^{2}$ \\ ${ }^{1}$ Department of Applied Microbiology and Brewing, Nnamdi Azikiwe University, Nigeria \\ ${ }^{2}$ Department of Applied Microbiology and Brewing, Enugu State University of Science and Technology, Nigeria
}

Received October 11, 2019; Revised November 28, 2019; Accepted December 4, 2019

Copyright $\odot 2020$ by authors, all rights reserved. Authors agree that this article remains permanently open access under the terms of the Creative Commons Attribution License 4.0 International License

\begin{abstract}
Crude and refined oil contamination of the aquatic environment is one of the major environmental problems that lead to unmanageable loss of biological life that impacts negatively on global economy particularly in the areas of petroleum production and transportation. Bioremediation potential of Chlorella vulgaris isolated from a pond in Uwani, Enugu State, Nigeria was studied using standard methods. The organism utilized crude oil heavily, kerosene moderately and petrol minimally as shown by the varying degree of turbidity produced during fourteen days of growth in mineral salts- oil medium. Biodegradation experiment was carried out for forty-two days and the results showed that there was a decrease in $\mathrm{pH}$ and an increase in the absorbance of the mineral salts - oil medium. The percentage of degradation of the crude oil, kerosene and petrol by the organism was $80 \%, 70 \%$ and $60 \%$ respectively. There was a reduction in the peak numbers and peak areas of the gas chromatograms of the total petroleum hydrocarbons and polyaromatic hydrocarbons of the residual crude oil as well as the residual kerosene and petrol. This work therefore indicated that the microalga $C$. vulgaris can be used for the bioremediation of crude and refined oil - polluted aquatic environments.
\end{abstract}

Keywords Crude Oil, Kerosene, Petrol, Chlorella vulgaris, Pond, Bioremediation

\section{Introduction}

Petroleum - based products are the major source of energy for the industry and daily life and petroleum is a major pollutant of the environment. Crude oil is a nationally - occurring complex mixture of hydrocarbons and non - hydrocarbon compounds which at appropriate concentration, possess a measurable toxicity towards living organisms. The toxicity of crude oil and petroleum products varies widely depending on their concentration, composition, environmental factors and the biological state of organisms at the time of the contamination [2].

Nigeria is continually faced with the challenges of oil spillage during exploration processes and transportation. Some of these challenges include contamination of nearby water bodies, death of aquatic organisms and contamination of farmlands. The health hazards created by oil exploration are the major contributors to the disease burden in oil - bearing communities [3]. One promising treatment method is to exploit the ability of microorganisms to remove these organic pollutants from contaminated sites. This alternative treatment strategy that is effective, minimally hazardous, economical, versatile and environmentally - friendly, is known as bioremediation [4].

Some microorganisms have the astonishing, naturally occurring catabolic diversity to degrade, transform or accumulate a huge range of products including hydrocarbons, polychlorinated biphenyls, radionuclides and metals [5]. Several microorganisms including fungi and bacteria are involved in biodegradation process. Biodegradation processes vary greatly but frequently, the final product is carbon IV oxide [6].

Most of the biological treatment technologies involve the use of bacteria but microalgae have already been applied for effluent treatment either as single species as is the case of Chlorella, Scenedesmus or Arthrospira [7,8] to treat and remove nitrogen, phosphorus and chemical demand in different types of effluents.

Algae play important roles in returning the environment altered by various contaminants to its original state. They are highly adaptive and can grow autotrophically, heterotrophically or mixotrophically in any environment resulting in higher concentration within themselves as compared to the surrounding water [9]. Microalgae are not unique in their bioremoval capabilities but they offer 
advantages over other biological materials in some conceptual bioremoval process schemes. Absorption of heavy metals by algae can be an effective process for the removal and recovery of heavy metals ions from aqueous solution [10].

Pollutant - degrading mixotrophic algae are excellent agents for the remediation of carbon - polluted environments. [11]. Examples of algae widely used and studied in bioremediation include Chlorella vulgaris, Anabaena inaequalis, Ascophyllum nodum and Nostoc spp. Chlorella vulgaris and Scenedesmus dimorphus are highly efficient for ammonia and phosphorous removal during biotreatment of oil - contaminated water.

Monteiro et al. [12] observed that strains of the Scenesdesmus obliquus tested have proven effective in removing a toxic heavy metal cadmium from aqueous solution, hence supporting their choice for bioremediation strategies of industrial effluents. Raposo et al. [13] analyzed the capacity of Chlorella vulgaris and the autochthonous flora of the effluents to remove some of the compounds present in the effluents.

Over the decades, oil spillage has adversely affected the rivers and streams especially in the oil - producing communities. Plants and animals at these contaminated sites are also adversely affected, hence the need to completely clean - up such sites, therefore in this work, the bioremediation of crude and refined oil - polluted fresh water using Chlorella vulgaris was carried out. It is hoped that this study will show that the micro alga Chlorella vulgaris isolated from a non-oil impacted environment (pond) possesses the ability to degrade crude oil and refined petroleum products and can be used to remediate oil spillage especially in fresh water environment and should not be regarded as a nuisance organism.

\section{Materials and Methods}

\subsection{Samples Collection}

The crude oil was obtained at Eleme Petrochemical Company Limited in Eleme Local Government Area of Rivers State, Nigeria. Samples of Kerosene (DPK) and Petrol (PMS) used were obtained from Anccor Filling Station, Uwani in Enugu South Local Government Area of Enugu State, Nigeria while water samples were obtained from a pond located at the premises of Commercial Agricultural Development Programme, Uwani, Nigeria, using sterile screw-capped bottles which were opened and inserted into the pond at a depth of $30 \mathrm{~cm}$ below the water surface with their mouths downward. They were thereafter turned so that the water flowed into them. The bottles were thereafter aseptically closed and transported to the laboratory in an ice packed container for the isolation, characterization and identification of Chlorella vulgaris.

\subsection{Isolation of Chlorella Vulgaris}

This was carried out using the spread plate method described by Robert [14]. An aliquot $(0.1 \mathrm{ml})$ of the pond water was spread on the surface of Petri dishes containing sterile Chlorella agar using a sterile glass rod. Triplicate plates were prepared which were covered and incubated in an inverted position at $28^{0} \mathrm{C}$ for 7 days.

\subsection{Characterization and Identification of the Isolates}

The colonial and microscopic characteristics of the isolates were determined according to the scheme of Janse et al. [15]. The isolates were placed in a drop of sterile distilled water on microscopic slides and a drop of iodine was applied to them. The slides were thereafter examined under a compound microscope. The isolates were identified using a catalogue of algae as done by Robert [14].

\subsection{Screening Test for Petroleum Hydrocarbons Utilization by Chlorella vulgaris}

The test was carried out using mineral salts medium as described by Olukunle [16]. The medium was composed of the following (g/l): $\mathrm{NaCl}, 10.0 ; \mathrm{MgSO}_{4} .7 \mathrm{H}_{2} 0,0.42 ; \mathrm{KCl}$, 0.29; $\mathrm{KH}_{2} \mathrm{PO}_{4}$ 0.83; $\mathrm{NaHPO}_{4}, 1.25$, Agar, 20.0 and distilled water, 1 litre. It was prepared and dispensed in $9 \mathrm{ml}$ amounts into test tubes. One millilitre of crude oil, kerosene and petrol was separately introduced into the test tubes which were thereafter capped and autoclaved at $121^{\circ} \mathrm{C}$ for fifteen minutes. Upon cooling, the tubes were inoculated with Chlorella vulgaris and incubated at $28^{\circ} \mathrm{C}$ for fourteen days in a rotary shaker operated at 75 revolutions per minutes after which they were observed for turbidity. Three uninoculated tubes each containing mineral salts -crude oil, mineral salts - kerosene and minerals oil -petrol served as controls

\subsection{Time Course Test for Petroleum Hydrocarbons Utilization by Chlorella vulgaris}

The mineral salts medium described by Olukunle [16] was used. It was prepared and dispensed in conical flasks in $99 \mathrm{ml}$ amounts. One millilitre (1\%) of crude oil, kerosene and petrol was introduced separately into the flasks which were after that autoclaved at $121^{0} \mathrm{C}$ for fifteen minutes and allowed to cool. Upon cooling, the flasks were separately inoculated with the organism separately and incubated for forty - two days in a rotary shaker operated at 75 revolutions per minute. The $\mathrm{pH}$ and absorbance were determined at the beginning and end of the experiment. The $\mathrm{pH}$ was determined using a $\mathrm{pH}$ meter (JENWAY) while the absorbance was determined using a Spectrophotometer. Three uninoculated tubes each containing mineral salts crude oil, mineral salts -kerosene and mineral salts -petrol were used as controls 


\subsection{Determination of the Residual Petroleum Hydrocarbons Content}

This was determined as described by Amadi [17]. The content of each flask was sterilized at $121^{\circ} \mathrm{C}$ for fifteen minutes at the end of the forty- two days of incubation to destroy the Chlorella vulgaris and thereafter transferred into a separating funnel. The residual crude oil, kerosene and petrol were thereafter extracted with toluene. The funnel was corked tightly and tilted for five minutes. The flask was shaken and occasionally refluxed to let out air and left to stand for 30 minutes. The toluene-oil mixture was collected in a sample bottle and analyzed spectrophotometrically by diluting the mixture with a known volume of toluene and reading the absorbance at 420nm. A standard graph was prepared using known volume of the toluene.

The residual hydrocarbon content was determined from the formula.

GR x WS

WT

Where GR = absorbance reading at 420nm X slope of the graph.

WS = initial volume of toluene used for the extraction.

$\mathrm{WT}=$ weight of the toluene-oil mixture.

Percentage residual oil $=$ oil applied - oil recovered X 100 oil applied

\subsection{Gas Chromatographic Profiles of the Petroleum Hydrocarbons before and after Degradation by Chlorella vulgaris}

The gas chromatographic profile of the petroleum hydrocarbons before and after degradation by $C$. vulgaris was determined as done by Onuorah et al. [18] using Agilent 6890 plus gas chromatograph equipped with ionizing detector, split injector and fused silica capillary column HP-1 of 30m length, $0.35 \mathrm{~mm}$ internal diameter and $0.5 \mathrm{~m}$ film thickness. The detector and injector temperatures were maintained at $300^{\circ} \mathrm{C}$ and $250^{\circ} \mathrm{C}$ respectively. The column temperature was programmed to rise from $80^{\circ} \mathrm{C}$ to $300^{\circ} \mathrm{C}$ with a rate of $3^{\circ} \mathrm{C} / \mathrm{min}$ and final time of fifteen minutes. Nitrogen $\left(0_{2}\right.$ free) was used as a carrier gas at a flow rate of $2 \mathrm{ml}$ per minute.

\section{Results}

The colonial and microscopic characteristics of the Chlorella vulgaris isolated from the pond water are shown in Table 1. The organism was small, green in colour, spherical, non - motile and non - flagellated with a single chloroplast with or without pyrenoid.
Table 1. Colonial and microscopic characteristics of the Chlorella vulgaris isolated from the pond

\begin{tabular}{|l|l|}
\hline $\begin{array}{l}\text { Colonial } \\
\text { characteristics }\end{array}$ & Microscopic characteristics \\
\hline $\begin{array}{l}\text { Colonies were small, } \\
\text { round and green in Petri } \\
\text { dishes. }\end{array}$ & $\begin{array}{l}\text { Colonies were small, non-flagellated, } \\
\text { non-motile, spherical with a single, } \\
\text { cup-shaped, thin chloroplast with or } \\
\text { without pyrenoid }\end{array}$ \\
\hline
\end{tabular}

Table 2 showed the result of the screening test for petroleum hydrocarbons utilization by Chlorella vulgaris. The organism utilized crude oil heavily, kerosene moderately and petrol minimally.

Table 2. Screening test for petroleum hydrocarbons utilization by Chlorella vulgaris

\begin{tabular}{|l|l|}
\hline Petroleum Hydrocarbons & Utilization by Chlorella vulgaris \\
\hline Crude oil & +++ \\
\hline Kerosene & ++ \\
\hline Petrol & + \\
\hline
\end{tabular}

$+++=$ heavy utilization

$++=$ moderate utilization

$+=$ minimal utilization

The changes in $\mathrm{pH}$ of the mineral salts -oil medium during forty-two days of degradation by Chlorella vulgaris are presented in Table 3 . The medium containing crude oil had the lowest final $\mathrm{pH}$ of 4.0 while that containing petrol had the highest $\mathrm{pH}$ of 4.7 .

Table 3. Changes in $\mathrm{pH}$ of the mineral salts - oil medium during forty two days of degradation by Chlorella vulgaris

\begin{tabular}{|l|l|l|}
\hline Petroleum Hydrocarbons & Initial pH & Final pH \\
\hline Crude oil & 7.2 & 4.0 \\
\hline Kerosene & 7.2 & 4.5 \\
\hline Petrol & 7.2 & 4.7 \\
\hline
\end{tabular}

Table 4 showed the changes in absorbance of the mineral salts - oil medium during forty-two days of degradation by Chlorella vulgaris. The organism had the highest absorbance in the medium containing crude oil while it had the lowest absorbance in the medium containing petrol.

Table 4. Changes in absorbance of the mineral salts - oil medium during forty-two days of degradation by Chlorella vulgaris

\begin{tabular}{|l|l|l|}
\hline $\begin{array}{l}\text { Petroleum } \\
\text { Hydrocarbons }\end{array}$ & $\begin{array}{l}\text { Initial } \\
\text { absorbance }\end{array}$ & $\begin{array}{l}\text { Final } \\
\text { absorbance }\end{array}$ \\
\hline Crude oil & 0.460 & 0.928 \\
\hline Kerosene & 0.416 & 0.852 \\
\hline Petrol & 0.464 & 0.875 \\
\hline
\end{tabular}

The residual oil content of the mineral salts -oil medium at forty-two days of degradation by Chlorella vulgaris is shown in Table 5. The residual oil content of the medium containing crude oil had the lowest volume while that containing petrol had the highest volume of oil recovered. 
Table 5. Residual oil content of the mineral salts - oil medium at forty two days of degradation by Chlorella vulgaris

\begin{tabular}{|l|l|l|l|}
\hline $\begin{array}{l}\text { Petroleum } \\
\text { hydrocarbons }\end{array}$ & $\begin{array}{l}\text { Initial oil } \\
\text { content }\end{array}$ & $\begin{array}{l}\text { Final oil } \\
\text { content }\end{array}$ & $\begin{array}{l}\text { Degradation } \\
\text { \% }\end{array}$ \\
\hline Crude oil & 1.0 & 0.2 & 80 \\
\hline Kerosene & 1.0 & 0.3 & 70 \\
\hline Petrol & 1.0 & 0.4 & 60 \\
\hline controls & 1.0 & 1.0 & 0 \\
\hline
\end{tabular}

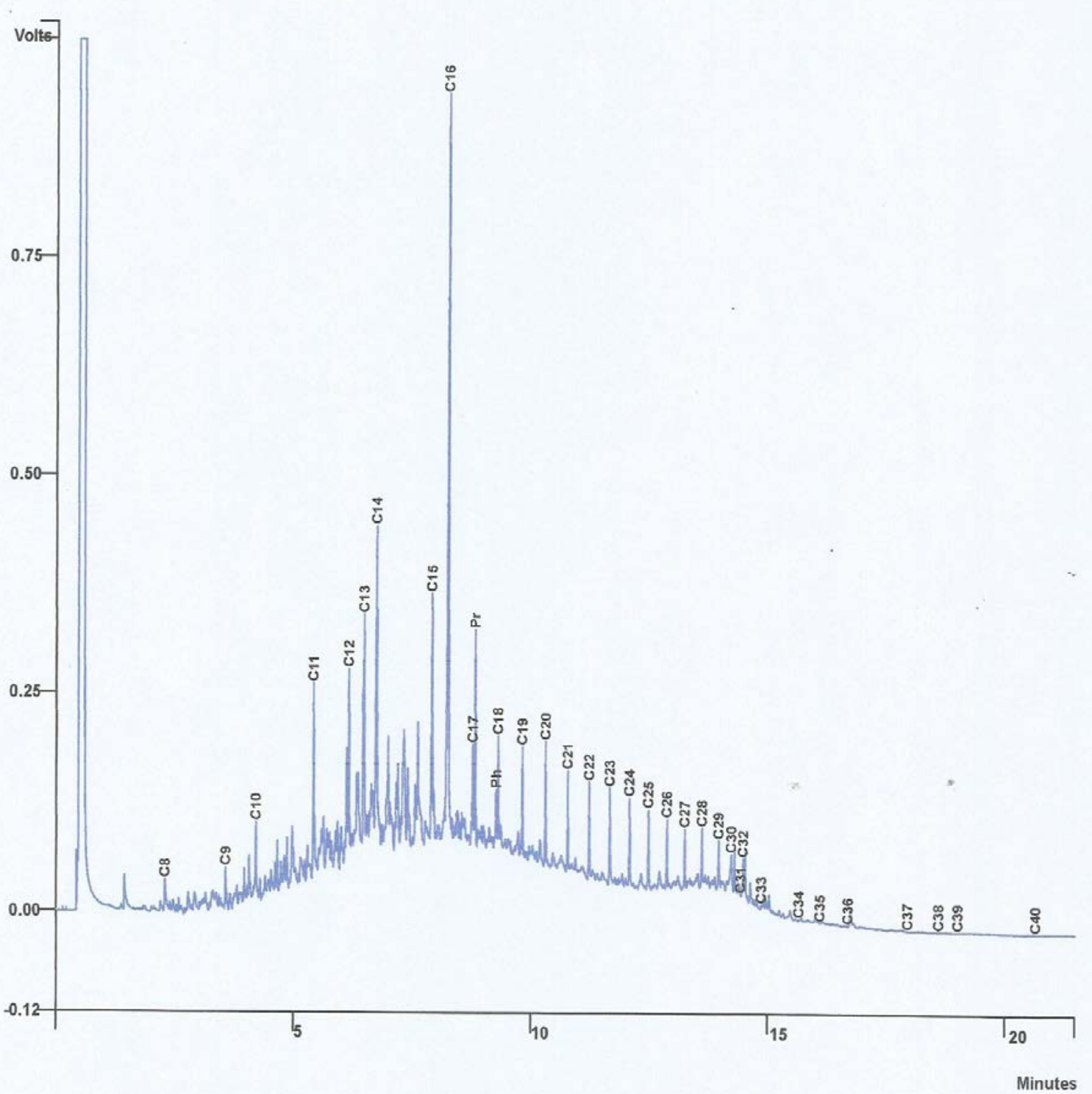

Figure 1. Gas chromatographic profile of the total petroleum hydrocarbons content of the unused crude oil

Figures $1-4$ showed the gas chromatographic profiles of the unused crude oil (total petroleum hydrocarbons and polyaromatic hydrocarbons), kerosene and petrol respectively. The peak areas were 13,434, 722; 2,919, 034; $13,955,470$ and 5,558, 402 for the total petroleum hydrocarbons and polyaromatic hydrocarbons of the unused crude oil, kerosene and petrol respectively. 


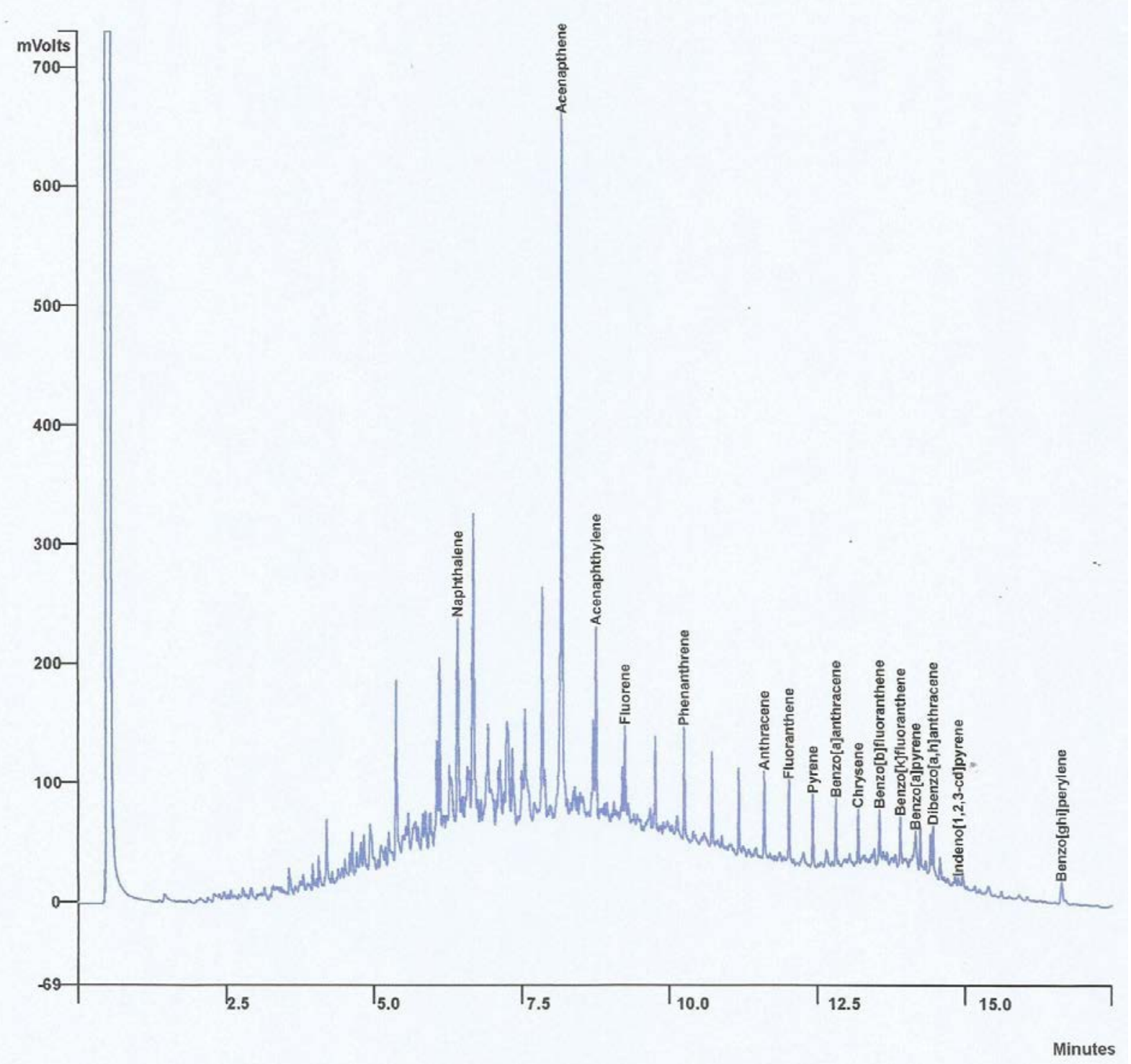

Figure 2. Gas chromatographic profile of the polyaromatic hydrocarbons of the unused crude oil 


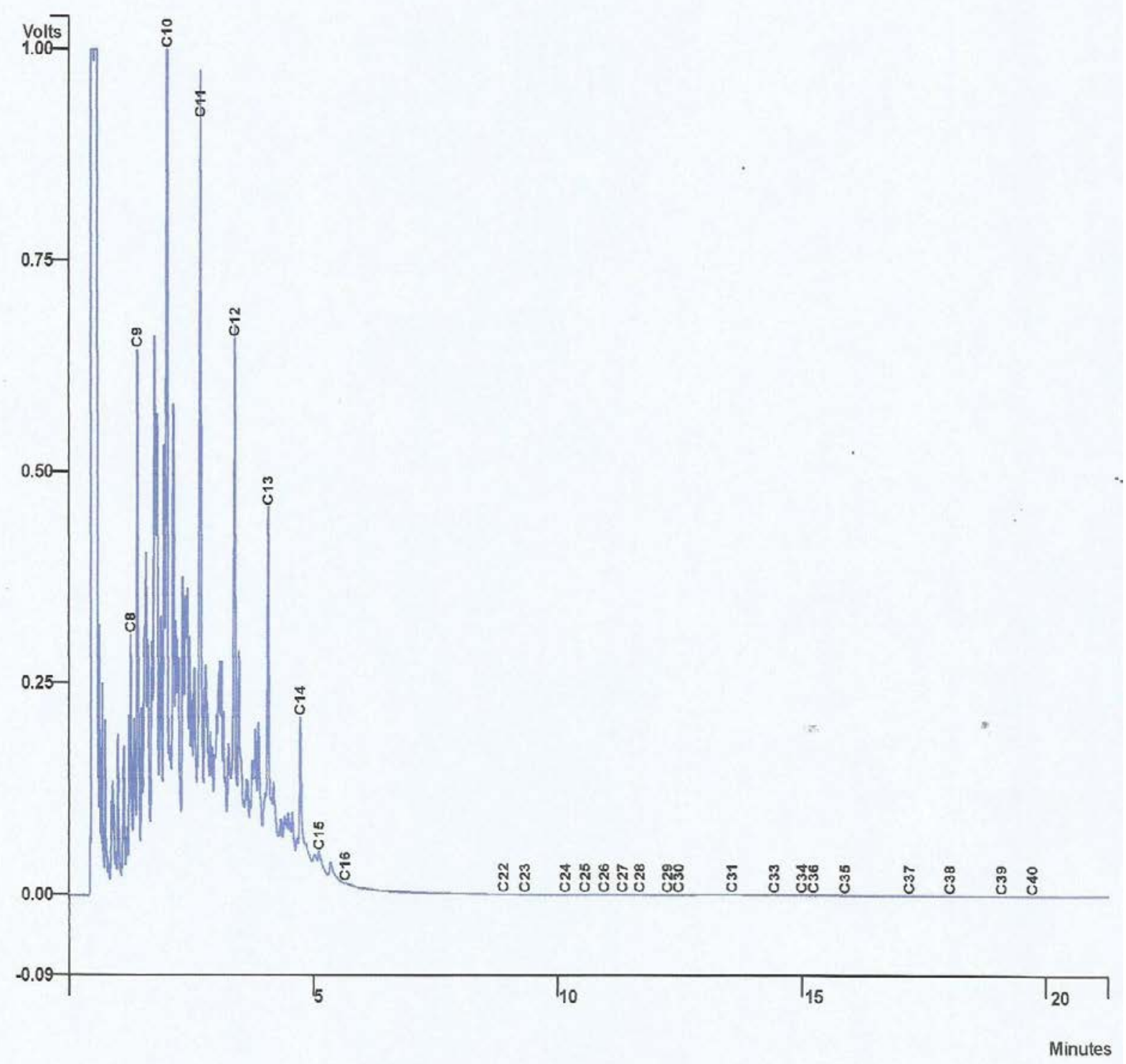

Figure 3. Gas chromatographic profile of the unused kerosene 


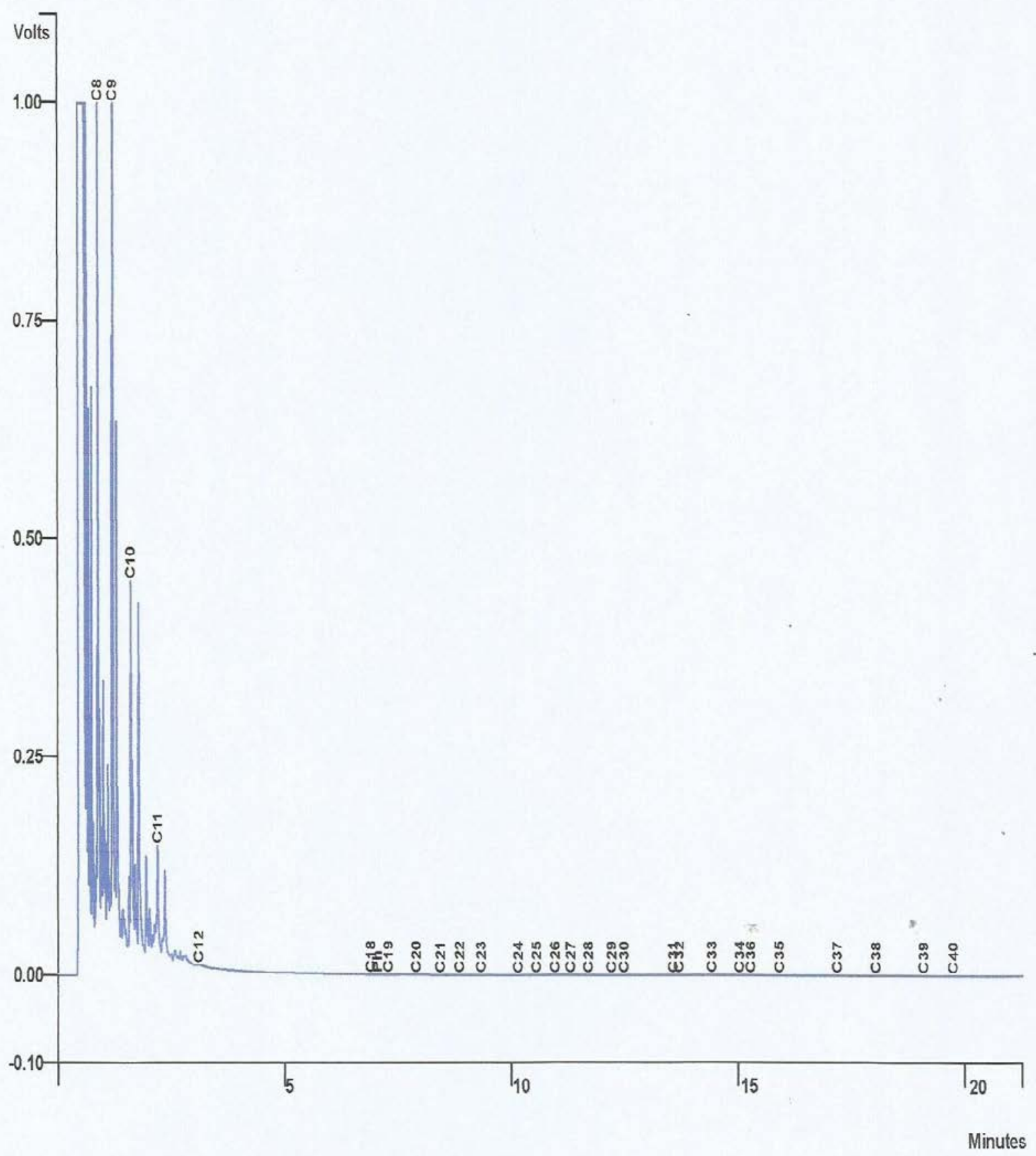

Figure 4. Gas chromatographic profile of the unused petrol

The gas chromatographic profiles of the residual crude oil, kerosene and petrol respectively are presented in Figures $5-8$. The peak areas of the total petroleum hydrocarbons and polyaromatic hydrocarbons of the residual crude oil, kerosene and petrol were 246,285; 109,387; 22,668 and 12,283 respectively. 


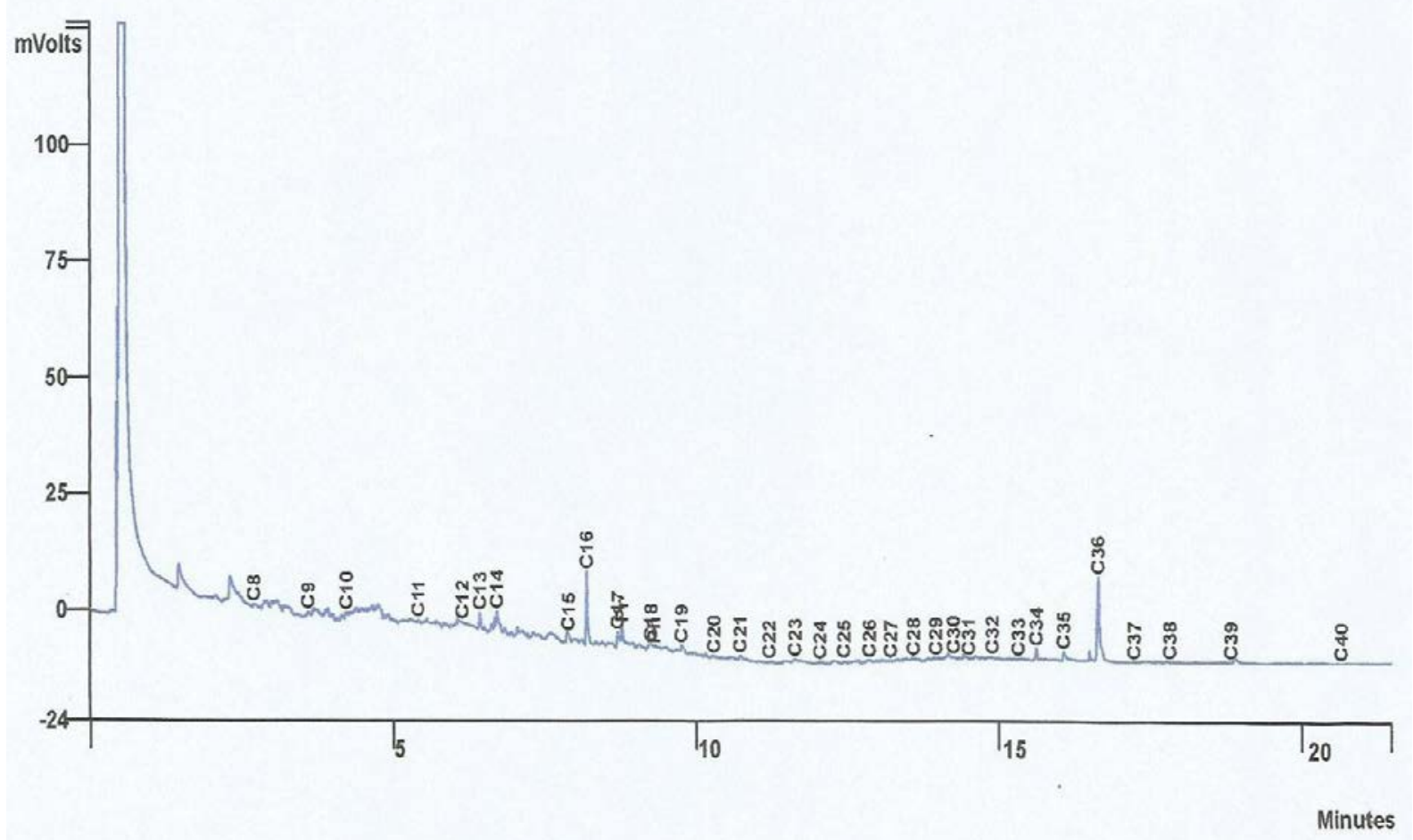

Figure 5. Gas chromatographic profile of the total petroleum hydrocarbons of the residual crude oil

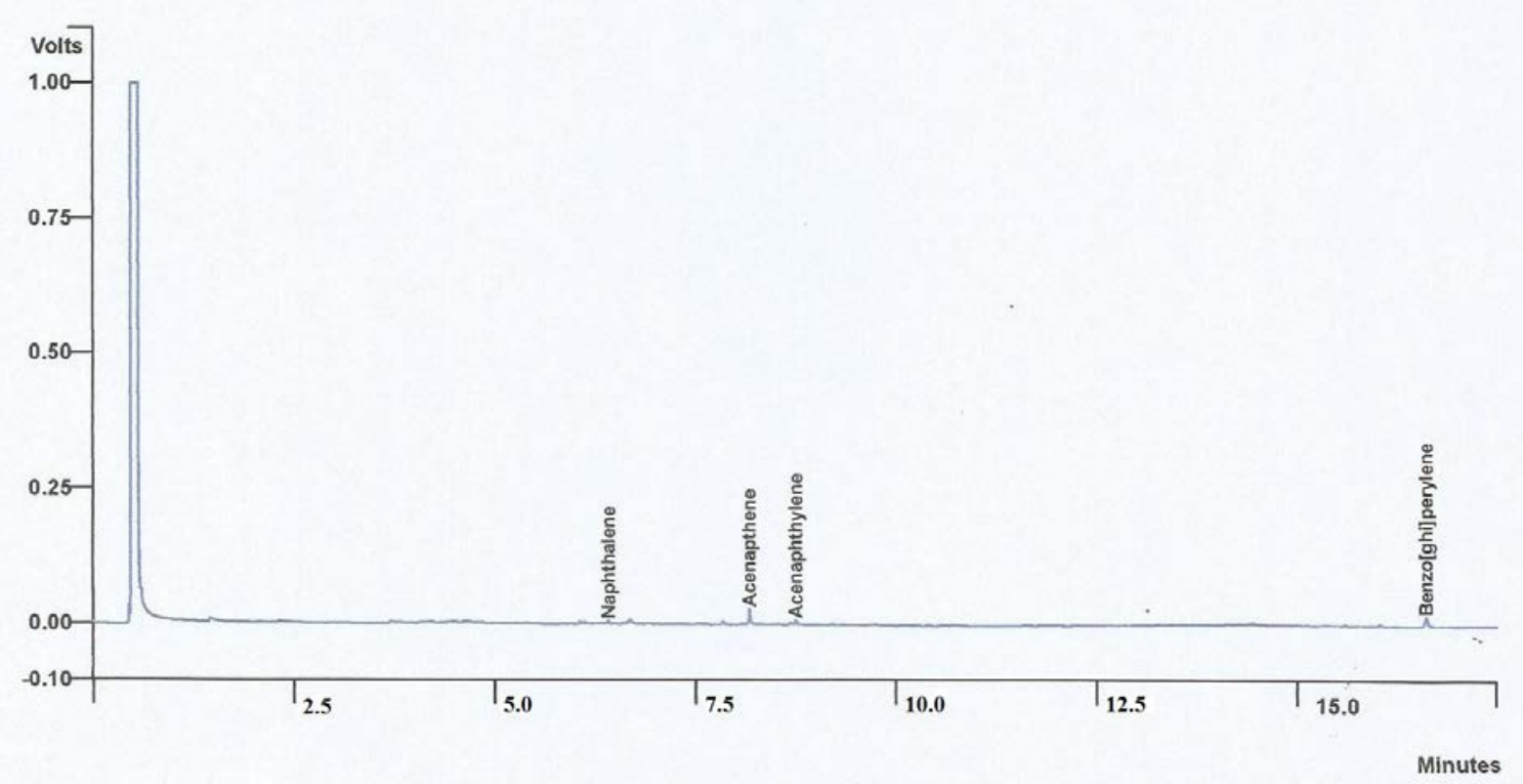

Figure 6. Gas chromatographic profile of the polyaromatic hydrocarbons of the residual crude oil 


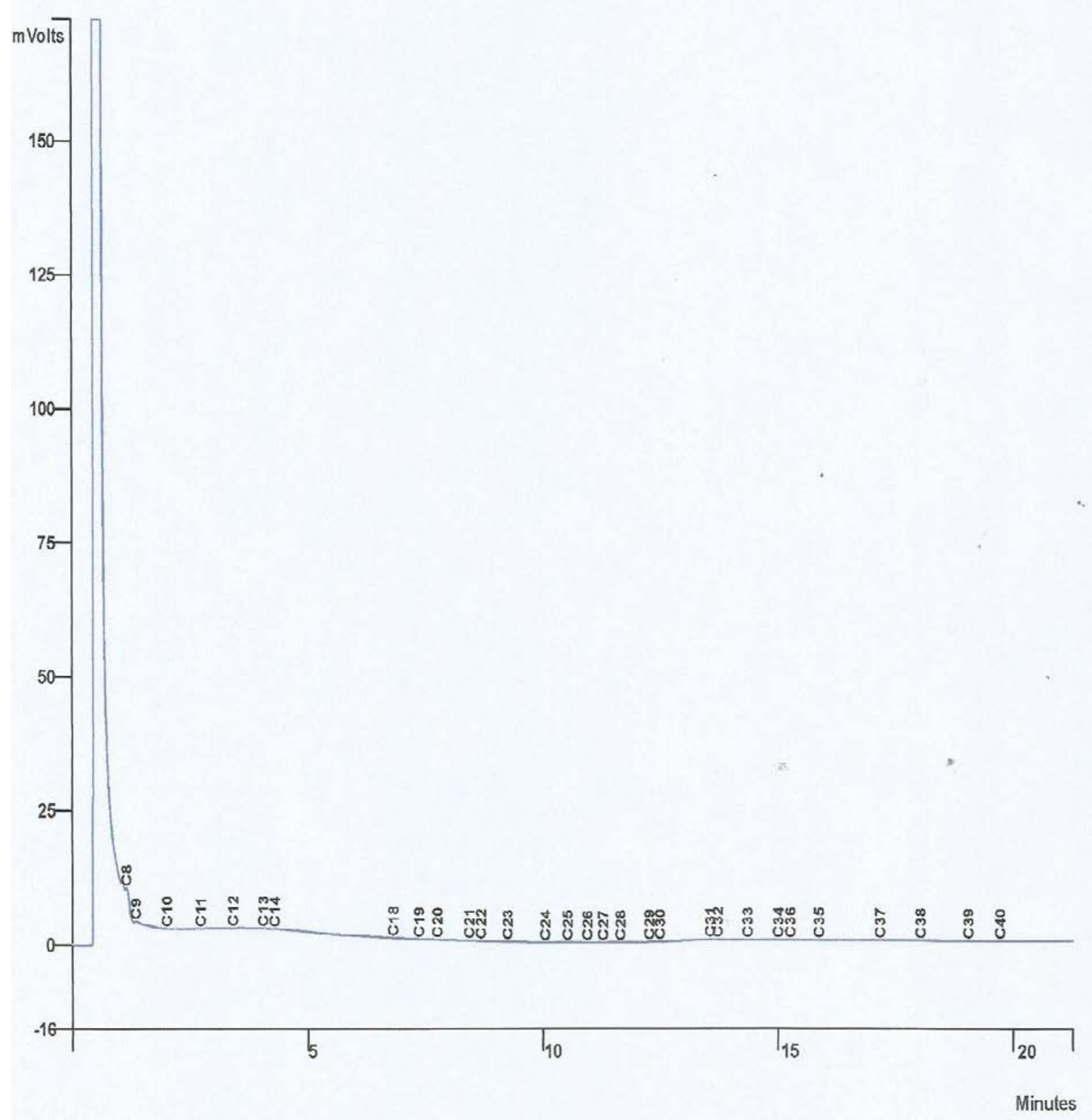

Figure 7. Gas chromatographic profile of the residual kerosene 


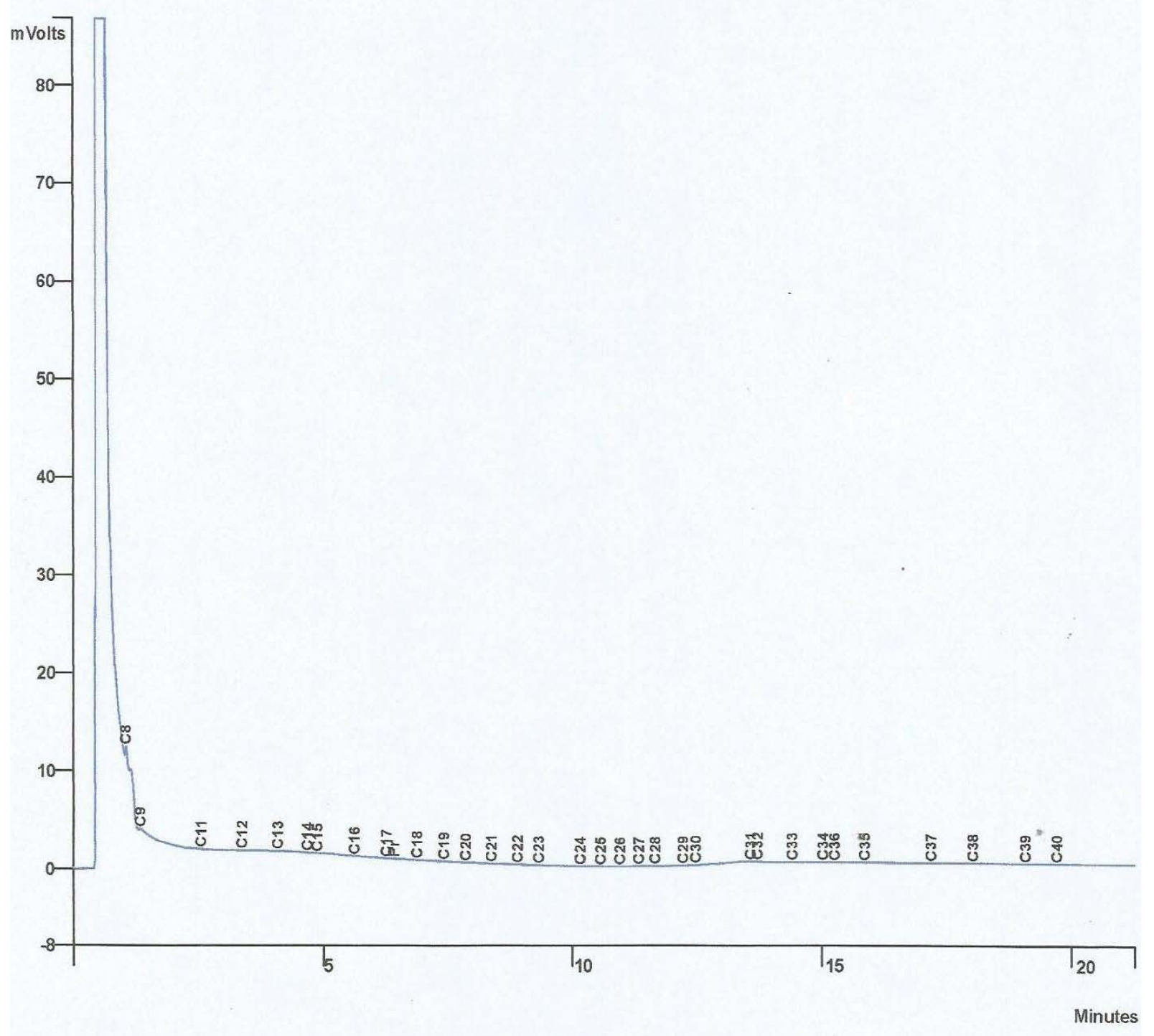

Figure 8. Gas chromatographic profile of the residual petrol

\section{Discussion}

The algae isolated from the pond water were identified as Chlorella vulgaris (Table 1). This result agreed with Janse et al. [15] who also identified Chlorella vulgaris from fresh water.

The result of the screening test for Petroleum hydrocarbons utilization by Chlorella vulgaris showed heavy crude oil utilization, moderate and minimal utilization of kerosene and petrol respectively as shown by the varying degree of turbidity produced in the mineral salts -oil medium (Table 2)

There was a progressive decrease in the $\mathrm{pH}$ of the mineral salts - oil medium at forty-two days of petroleum hydrocarbons degradation by Chlorella vulgaris from the neutral to the acidic level. The highest final $\mathrm{pH}$ (4.7) was obtained in the mineral salts - petrol medium inoculated with Chlorella vulgaris, final $\mathrm{pH}$ (4.5) was obtained in the mineral salts - kerosene medium inoculated with $C$. vulgaris while the lowest $\mathrm{pH}$ (4.0) was obtained in the mineral salts - crude oil medium inoculated with $C$. vulgaris (Table 3 ).

The reduction in $\mathrm{pH}$ may be attributed to the production of acidic metabolites by $C$. vulgaris while growing in the mineral salts - oil medium. This result agreed with Rahman et al. [19] that reported that the utilization of crude oil as sole source of carbon and energy by microorganisms resulted in their growth and the concomitant production of acids.

There was an increase in the absorbance of the mineral salts -oil medium during the forty-two days of the degradation by Chlorella vulgaris (Table 4). The absorbance of the mineral salts - crude oil medium containing C. vulgaris was higher than that of the kerosene and petrol. The increase in absorbance indicated growth as a result of the utilization of oil as carbon and energy source by the $C$. vulgaris.

The residual oil content of the mineral salts - crude oil 
medium was higher than those of the media containing kerosene and petrol (Table 5). The mineral salts - crude oil medium inoculated with $C$. vulgaris had the highest degradation percentage $(80 \%)$ while the mineral salts petrol medium inoculated with $C$. vulgaris had the lowest degradation percentage $(60 \%)$. However, there was no degradation in the uninoculated tubes. Crude oil was degraded more than the kerosene and petrol .This may be attributed to the fact that crude oil is a complex mixture of hundreds of hydrocarbons and other substances such as nitrogen, phosphorus, sulphur hydrogen and oxygen.These constituents of crude oil must have favoured the increased growth and proliferation of the C. vulgaris, hence their greater utilization of crude oil more than kerosene and petrol which are processed petroleum products. The kerosene and petrol may have lost many of these constituents during refining.

The gas chromatographic profiles of the unused crude oil (total petroleum hydrocarbons and polyaromatic hydrocarbons) and unused kerosene and petrol showed high peak numbers and peak areas (figures 1-4). A decrease in the peak numbers and peak areas (figures 5-8) of the residual crude oil, kerosene and petrol indicated a reduction in the gas chromatographic detectable hydrocarbons after forty-two days of inoculation with $C$. vulgaris, hence the utilization of such oil by the organism. This result is in agreement with Onuorah et al. [18] who reported a decrease in the peak numbers and peak areas of residual oil after forty-two days of utilization by bacterial consortia

El-Sheekh et al. [20] evaluated the potential of two green algae Scenedesmus obliquus and Chlorella vulgaris to degrade crude oil. Experiments were performed by incubating algal cultures with $0.5,1.0,1.5$ and $2.0 \%$ crude oil for fifteen days under heterotrophic conditions. The highest growth of $S$. obliquus occurred at $0.5 \%$ crude oil concentration while $C$. vulgaris had its highest growth at $2.0 \%$ crude oil concentration. They also reported that both algae can grow and degrade oil effectively when incubated with low concentration of oil.

\section{Conclusions}

This study showed that the remediation of crude oil (total petroleum hydrocarbons and polyaromatic hydrocarbons), kerosene and petrol - polluted sites by Chlorella vulgaris is attainable, as it is cheap and leads to environmentally - friendly products. The application of the alga in biomonitoring and restoration of aquatic systems favours the biodegradation and remediation of many organic pollutants. Chlorella vulgaris can therefore be considered as a key component in the clean - up strategy for petroleum hydrocarbons remediation.

\section{REFERENCES}

[1] Mehdi, H. and Giti, E. (2008). Investigation of alkane biodegradation using the microtiter plate method and correlation between biofilm formation, biosurfactant production and crude oil biodegradation. International Biodeterioration and Biodegradation. 62 (2): 170-178.

[2] Obire, O. and Anyanwu, E. C. (2009). Impact of various concentrations of crude oil on fungal populations of oil. International Journal of Environmental Science and Technology. 6 (2): 211-218.

[3] Best, O. and Seiyefa, B. (2013). The human health implications of crude oil spills in the Niger Delta, Nigeria: An interpretation of published studies. Journal of Nigeria Medical Association. 54 (1): 10-16.

[4] Finley, S. D; Broadbelt, L. J. and Wand Hatzimanikatis, V. (2010). In silico feasibility of novel biodegradation pathways for 1,2,4-trichlorobenzene. BMC Systems Biology. 4 (7): 4-14.

[5] Leitao, A. L. (2009). Potential of Penicillium species in the bioremediation field. International Journal of Environmental Research and Public Health. 6 (4): 1393-1417.

[6] Pramila, R; Padmarathy, K; Vjaya Ramesh, K. and Mahalakshimi, K. (2012). Brevibacillus parabrevis, Acinetobacter baumannii and Pseudomonas Citronellolis-potential candidates for biodegradation of low density polyethylene (LDAP). Journal of Bacteriology Research. 4 (1): 9-14.

[7] Lee, K. and Lee, C. (2001). Effect of light /dark cycles on waste water treatments by microalgae. Biotechnology and Bioprocess Engineering. 6 (3): 194-199.

[8] Lima, S. A; Raposo, M. F; Castro, P. M. and Morais, R.M. (2004). Biodegradation of p-chlorophenol by a microalgae consortium. Water Research. 38 (1): 97-102.

[9] Shamsuddoha, A. S. M; Bulbul, A. and Imamul Huq, S. M. (2006). Accumulation of arsenic in green algae and its subsequent transfer to the soil-plant system. Bangladesh Journal of Microbiology. 22 (2): 148 -151.

[10] Kaewsarn, P. (2002). Biosorption of copper (II) from aqueous solutions by pre-treated biomass of marine algae, Padina sp. Chemosphere. 47: 1081 - 1085.

[11] Subashchandrabose, S. R., Ramakrishnan, B., Megharaj, M., Venkateswalu, K. and Naidu, R. (2013). Mixotrophic cyanobacteria and microalgae as distinctive biological agents for organic pollutant degradation. Environment international. 51: 59 - 72 .

[12] Monteiro, C. M., Castro, P.M.L. and Malcata, F.X. (2009). Use of the microalga Scenesdesmus obliquus to remove cadmium cations from aqueous solutions. World Journal of Microbiology and Biotechnology. 25: 1573 - 1578. 
[13] Raposo, M.F.J., Oliviera, S.E., Castro, P.M., Bandarra, N.M. and Morais, R.M. (2010). On the utilization of microalgae for brewery effluent treatment and possible applications of the produced bimass. Journal of the Institute of Brewing. 116(3): $285-292$.

[14] Andersen, R.A. (2005). Algal culturing techniques. Provasoli-Guillard National Centre for Marine Algae and Microbiota, Bigelow. Phycological Society of America, Elsevier Academic Press. Pp 3-12.

[15] Janse van Vuuren, S.J. (2006). Easy identification of the most common freshwater algae: A guide for the identification of microscopic algae in South African Freshwaters. Resource Quality Services, United States of America. Pp 134 - 135.

[16] Olukunle, O.F. (2013). Characterization of indigenous microorganisms associated with crude oil- polluted soil and water using traditional techniques. Microbiology Journal. 3(1): 1-11.

[17] Amadi, A. (1992). An assessment of the performance of some petroleum hydrocarbon - degrading microorganisms in aqueous axenic culture. Discovery and innovation. 4(4): $61-67$.

[18] Onuorah Samuel, Idabor Simon and Odibo Frederick (2018). Evaluation of the potential of indigenous bacterial consortium in the remediation of Ogoniland crude oil polluted rivers. American Journal of Life Science Researches. 6(4): 174-187.

[19] Rahman, K.S.M., Thahira - Rahman, J., Lakshmana perumalsamy, P. and Banat, I.M. (2002). Towards efficient crude oil degradation by a mixed bacterial consortium. Bioresource Technology. 85(3): 257 - 261.

[20] El - Sheekh M.M; Hamouda, R.A. and Nizam, A.A. (2013). Biodegradation of crude oil by Scenedemus obliquus and Chlorella vulgaris growing under heterotrophic conditions. International Biodeterioration and Biodegradation. 82: 67 72. 